\title{
Knowledge of Partial Awareness in Disorders of Consciousness: Implications for Ethical Evaluations?
}

\author{
Orsolya Friedrich
}

Received: 8 August 2011 / Accepted: 21 November 2011 / Published online: 9 December 2011

(C) The Author(s) 2011. This article is published with open access at Springerlink.com

\begin{abstract}
Recent results from neuroimaging appear to indicate that some patients in a vegetative state have partially intact awareness. These results may demonstrate misdiagnosis and suggest the need not only for alternative forms of treatment, but also for the reconsideration of end-of-life decisions in cases of disorders of consciousness. This article addresses the second consequence. First, I will discuss which aspects of consciousness may be involved in neuroimaging findings. I will then consider various factors relevant to ethical end-of-life decision-making, and analyse whether and to what extent the above consequence applies to these factors. It will be shown that knowledge of the existence of partial awareness in patients with disorders of consciousness only influences end-of-life decision-making if certain background assumptions are made.
\end{abstract}

Keywords Disorders of consciousness - Awareness · End-of-life decisions $\cdot$ Neuroimaging

O. Friedrich $(\bowtie)$

Institute of Ethics, History and Theory of Medicine, LMU Munich,

Lessingstr. 2, 80336 Munich, Germany

e-mail: orsolya.f@gmx.net

\section{O. Friedrich}

Institute of Neuroscience and Medicine, Ethics

in the Neurosciences (INM-8), Jülich Forschungszentrum,

Jülich, Germany
Patients in a vegetative state and decisions about lifesustaining treatment in such cases have often been the focus of media attention. ${ }^{1}$ The frequently prolonged duration of the vegetative state and uncertainty about the patient's state of awareness play a key role in ethical debates. Recent findings in the neurosciences appear to indicate that patients in a vegetative state may, contrary to clinical diagnostic criteria, be conscious, in terms of being aware. To what extent, however, do such findings influence decisions made concerning life-sustaining treatment, particularly the decision on whether or not to withdraw artificial nutrition and hydration? ${ }^{2}$ Even if we consider changing the diagnosis in the case of inconsistent but clear evidence of consciousness ${ }^{3}$ to the minimally conscious state, the question remains: does knowledge of partial awareness in disorders of consciousness change the normative evaluation of whether or not to withdraw artificial nutrition and hydration? Or does this evaluation depend more on theoretical assumptions?

\footnotetext{
${ }^{1}$ See for example [42] for a discussion of media coverage of the vegetative state.

${ }^{2}$ Withdrawing artificial nutrition and hydration is one of the most challenging ethical questions in the field of end-of-life decision-making for disorders of consciousness. See [24].

${ }^{3}$ [8], p. 24. Further down I will specify the two diagnoses and the locked-in syndrome. In this paper I refer to the disorders of consciousness known as the vegetative state and the minimally conscious state.
} 
After briefly describing the neuroscientific findings regarding the vegetative state, I will first consider the question which kind of awareness or characteristics of consciousness are being discussed. I then pose the principal question of this article - namely, whether these findings change any aspects of the normative assessment of end-of-life decisions with regard to disorders of consciousness. To address this question, I will discuss various theoretical views that appear to be critically important in normative end-of-life decision-making and awareness. I argue that, depending on the theory, such theoretical bases may have a greater influence on end-of-life decision-making with regard to these patients than knowledge of potential awareness itself.

Regarding end-of-life decisions, particularly for those decisions concerning whether or not to withdraw artificial hydration and nutrition, I will analyse to what extent the knowledge of awareness is critical for attribution of moral status within a particular moral theory. I will also clarify the significance of theoretical assumptions about personal identity for those decisions in connection with knowledge of awareness in patients with disorders of consciousness. The significance of the principle of respect for autonomy in the context of different states of awareness in patients with disorders of consciousness and end-of-life decisions, like whether or not to withdraw artificial hydration and nutrition, will also be described.

\section{Disorders of Consciousness and New Findings on Potential Awareness}

Characteristic of the vegetative state and essential for a clinical diagnosis thereof is the absence of visible evidence of intact awareness. According to the neurological definition of the vegetative state, arousal is still present in these patients, but they show no signs of awareness of themselves or of the environment or of purposeful activity. ${ }^{4}$ A vegetative state is a post-comatose state that develops after severe brain damage of varying causes such as hypoxia or traumatic head injuries. Independent respiratory function may still be present. Although patients in a vegetative state exhibit sleep-wake cycles, reflex

\footnotetext{
$\overline{{ }^{4} \text { See [8], p. } 23} \mathrm{f}$.
}

behaviour in response to painful stimuli, and involuntary motor functions, they do not show voluntary reactions or other signs of perception or awareness. ${ }^{5}$

Diagnosis is actually primarily made clinically. Recent findings using neuroimaging techniques such as functional magnetic resonance imaging (fMRI) suggest, however, that diagnosis using such techniques is essential. Specifically, they may provide evidence that certain characteristics of awareness have been retained in the vegetative state. Therefore, they could help to differentiate between patients in a vegetative state, in a minimally conscious state and in a locked-in syndrome and reduce misdiagnosis. ${ }^{6}$ After clinical observation, patients are diagnosed as being in a minimally conscious state rather than a vegetative state if they show some evidence of awareness (even if inconsistent and variable, but reproducible and distinguishable from reflexes), such as following simple commands. Locked-in syndrome is not a disorder of consciousness, but a neurological state in which patients have no motor function but intact awareness, perception and cognition. ${ }^{7}$ The recently postulated assumption that awareness is present in some cases of vegetative-state patients arises from the identification of activity patterns in the brain that are similar to those of healthy people following external stimulation. Most of the fMRI findings obtained regarding the state of awareness of these patients do not actually indicate elevated activity in higher-order association areas. ${ }^{8}$

\footnotetext{
$\overline{{ }^{5} \text { See [44], [16] }}$, p. 57 ff.; and [15], p. 77.

${ }^{6}$ Cases of misdiagnosis between the vegetative state and the minimally conscious state (sometimes even the locked-in syndrome) are not rare, see $[19,18,20]$. One main difference between patients in a locked-in syndrome and patients in a vegetative state or a minimally conscious state is that in some cases they have the ability to communicate through eye movement or brain-computer-interfaces. For more on this topic, see [4].

${ }^{7}$ See [8], p. 25 and p. 27. Cortical function in the vegetative state is usually restricted to cortical islands, which are not integrated within functional networks, but the functions of the diencephalon and brainstem remain largely intact. In the minimally conscious state there seems to be functional connectivity within the large cortical networks. In the lockedin syndrome, the global brain metabolism and cortical networks are usually normal, but there is extensive paralysis due to the disruption of the pyramidal tract or the motor efferences in the peripheral nervous system. For further information see [8], p. $23 \mathrm{f}$.

${ }^{8}$ See [16], p. 77; [26, 27].
} 
However, some studies postulate a significant increase of activity in areas of the cortex, which could allow one to infer that partially intact awareness is present. For example, patients have been asked to imagine particular activities that were familiar to them. After this request, some patients show an increase in the activity of the motor cortex similar to that observed in healthy individuals. ${ }^{9}$ Another study suggests the ability of wilful modulation of brain activity in disorders of consciousness by answering yes-or-no questions during neuroimaging. ${ }^{10}$ There are also individual studies that postulate that patients in a vegetative state exhibit a similar emotional response after being addressed by family members to that observed in healthy people. Researchers reached this conclusion after detecting variation in activity around the amygdala depending on whether the patients were addressed by family or by strangers or were directly or indirectly addressed. ${ }^{11}$ A recent study by Boly et al. could change the research focus on vegetative state and awareness again. They postulate an impairment of backward connectivity from frontal to temporal cortices in a vegetative state as essential to differentiate these patients from controls with neuroimaging techniques. $^{12}$

If patients in a vegetative state are aware of themselves and their environment to some extent (as indicated in the mentioned studies), then they would probably be diagnosed as being in a minimally conscious state. Therefore, the question of the influence of knowledge (clinical or through neuroimaging) of partial awareness on normative assessment of end-of-life decisions applies as well to the vegetative state as to the minimally conscious state. The question of such influence to normative assessment also applies to the locked-in syndrome, but as we will see later, the normative assessment of end-oflife decisions is clearly transformed if the patients

\footnotetext{
$\overline{9}$ See [16], p. 77; [11, 34, 37, 38, 44].

${ }^{10} \mathrm{See}[35]$. It has to be said that the results of this study apply to patients in a vegetative or minimally conscious state. The problem of making a distinction between a clinically diagnosed vegetative state and a minimally conscious state remains though for all cited studies.

${ }^{11}$ See [12].

${ }^{12}$ See [7]. It should be noted here that in the philosophy of mind the idea that everything about the quality of mental experiences can be learned on the basis of neuronal activity is highly controversial. See the "explanatory gap argument" posited by [28], and the "knowledge argument" posited by [23].
}

become able to sufficiently communicate wishes as is sometimes possible in the locked-in syndrome (through eye movements or $\mathrm{BCI}$ ).

To answer the main question it is helpful to have a closer look at the following question: which aspects of awareness could be indicated in patients with disorders of consciousness based on the findings that were mentioned? In the theoretical debate concerning consciousness, different aspects have been emphasised and discussed. For example, when alluding to the experiential nature of feelings and perceptions there is talk of phenomenal consciousness. Intentionality can constitute an additional structural feature of human consciousness. Intentionality involves a subject referring to an object or to a situation, more generally: intentionality is about the directness of mental states. ${ }^{13}$ Access consciousness requires that the subject has access to the representational content of a mental state. This access may have various conditions. It may be sufficient if the representational content of a state initiates or coordinates the course of action, but it may also be necessary that the subject is able to report the representational content using language. ${ }^{14}$ One speaks of self-consciousness if the subject not only refers to him- or herself but also experiences him- or herself as someone who is in a certain mental state, that is, when he or she is aware of his or her own state of consciousness. ${ }^{15}$

The cited findings do not constitute evidence for self-consciousness, but the missing of evidence does not necessarily mean that it is impossible that patients with disorders of consciousness have selfconsciousness. More evidence seems to be given by the findings for qualitative mental experience or phenomenal consciousness in disorders of consciousness if patients show increased neuronal activity when addressed by family members. Likewise, this could

\footnotetext{
${ }^{13}$ For a short description of the long debate on the relationship of consciousness and intentionality, see for example [47]. Some philosophers would argue that consciousness is separate from intentionality and cannot be derived from it; others consider consciousness and intentionality as inseparable, see [47].

${ }^{14}$ See [39], 77; [49], p. 77 f. The differentiation between access consciousness and phenomenal consciousness was first made by Ned Block, see [6]. For a summary of the discussion of intentionality and the interrelationship between intentionality and phenomenal consciousness, see [31].

${ }^{15}$ See [49], p. 64 f. For more on pre-reflective selfconsciousness, self-reference and self-knowledge in relation to self-consciousness, see for example [14, 46, 50].
} 
indicate intentionality, as could detection of increased activity in higher association areas following instructions.

Such findings could be highly relevant for the everyday care of patients with disorders of consciousness. Family members may for example feel more compelled to directly address patients, if signs of awareness could be demonstrated through neuroimaging in patients where clinical signs are absent. Those findings could also help reduce the amount of misdiagnoses.

But what do these findings mean for moral judgements in end-of-life decisions involving patients with disorders of consciousness?

\section{Aspects of Normative End-of-Life Decision-Making Involving Patients with Disorders of Consciousness}

Before I examine this question on the basis of an evaluation of autonomy, I will briefly describe how the principle of respect for autonomy is usually incorporated into decision-making processes in medical ethics. Ethical obligations towards patients and third parties in medical ethics are usually evaluated using the moral approach of principlism. Four 'midlevel' principles - respect for autonomy, beneficence, non-maleficence and justice-come into play in the assessment process. These principles are balanced against one another in a given case. ${ }^{16}$ Ethical coherence forms a theoretical foundation for such an assessment process. ${ }^{17}$ In practical decision situations it is always critical to know whether the principles used in the assessment derive their meaning from common sense or whether it is sought to justify the individual principles. At least in my opinion, despite the fitness of the practical application of these principles, the theoretical foundations on which the individual principles are based in the case of a particular 'user' should always remain apparent. It is not possible to elaborate all four principles in detail here in reference to disorders of consciousness. I will also refrain from undertaking a balancing of these principles for disorders of consciousness in the end. ${ }^{18}$

\footnotetext{
${ }^{16}$ For a detailed description of this approach, see [3]. For a critical discussion of principlism, see e.g. [17].

${ }^{17}$ On the subject of ethical coherence, see e.g. [10, 51].

${ }^{18}$ See [24] for an attempt to balance the cited four principles for the vegetative state.
}

Instead, I will consider some fundamental aspects of these principles in light of their theoretical foundations and in reference to disorders of consciousness.

In a discussion of moral status, various options for establishing a theoretical foundation for the principles of beneficence and non-maleficence become apparent. In the process of reflection on the four mid-level principles, we are led again to classical moral philosophical approaches, approaches which may serve as a basis for these principles in the present case, i.e. the rendering of normative assessments in end-of-life decisions for disorders of consciousness.

First, I will seek to contribute to reflections on the principle of respect for patient autonomy. In doing so, I hope to clarify which fundamental background assumptions characterise this principle and how this in turn influences the end-of-life decision-situation with regard to patients with disorders of consciousness. Picking this principle first is justified by its importance for end-of-life decisions. The principle of respect for autonomy is represented in a living will and in substituted judgements. Particularly in these cases, this principle is dependent on the assumed theory of personal identity.

\section{Autonomy and Personal Identity}

In medical debates, autonomy is usually defined as both a negative and a positive freedom, that is, the absence of external compulsions and autonomy as the possession of actual capacities. The term 'autonomy' is derived from the Greek autos ('self') and nomos ('law', 'determination'). Even at the terminological level, there are two primary features apparent when referring to autonomy: self-determination and selflegislation. In ancient times, self-legislation had strong connections to politics while the reference to individual autonomy only developed much later in philosophy. The opportunity and ability to mould one's own life according to one's own plans constitutes another essential feature of autonomy. ${ }^{19}$ The latter also produces certain regularities and makes people predictable. These different aspects of autonomy are associated with different conditions necessary to satisfy autonomy.

Demands for autonomy in medical ethics are usually associated with the commonly understood

\footnotetext{
$\overline{{ }^{19} \text { See [3], p. } 99}$ f.; [22], p. 53; [2], p. 9.
} 
definition of autonomy as self-determination and require some standards of competence. The person must be able to understand information and his or her own situation and any consequences resulting from the situation to a substantial degree, to adequately process information, to be able to specify reasons, to be able to communicate preferences, to be able to justify preferences and actions and so on. The person must also be able to act intentionally, employ appropriate means for goals he or she has set, that is, to be able to display a certain instrumental rationality as well as be able to implement his or her goals. There should be no further influences that control or determine a person's actions. ${ }^{20}$

We can also speak of self-determination when a person is able to mould his or her life in accordance with his or her own 'higher-order' desires. This means that he or she does not pursue every arbitrary desire ad hoc, but rather follows desires that he or she perceives as being of higher value. This goes beyond means-end reasoning and its implementation, as well as the conditions that are imposed with such an understanding of autonomy. Within this meaning of self-determination, both a certain biographical identity is required as well as a reflexive identification with a person's own desires. Through the continual implementation of this human ability, the actions of humans also become more predictable for others. This, in turn, is an essential condition of being able to make a substituted judgement for humans in cases such as disorders of consciousness. ${ }^{21}$

The question here is: can patients with a disorder of consciousness satisfy any one of the conditions of autonomy, with or without certain characteristics of awareness? The practical verifiability of autonomy is inherently afflicted with a range of problems. ${ }^{22}$ However, for patients with a disorder of consciousness, it is unlikely that even minimal conditions of selfdetermination can be met, neither using clinical observation nor applying the findings from

\footnotetext{
${ }^{20}$ See [3], chapter 4. On the topic of instrumental reasons, see e.g. [45].

${ }^{21}$ For more on reflective identification with wishes and autonomy, see [41]; for more on the original development of the theory of second-order volitions, see [13]. Autonomy can be understood in a Kantian manner as well as self-legislation. It presupposes self-determination, but demands even more of moral subjects.

${ }^{22}$ For a review of empirical approaches to assess Patients' Decision Making Competence, see [54].
}

neuroimaging about potentially present awareness. This assessment would change rapidly if neuroscientific techniques could help patients to communicate their actual will, as in cases of patients with locked-in syndrome. Probably the diagnosis of disorder of consciousness would change then as well. The question of whether the findings from neuroimaging change something in the prospective autonomy of the patients or in a substituted judgement process appears, therefore, to be far more relevant for patients with disorders of consciousness.

Recognising prospective autonomy in the context of a living will or establishing a substituted judgement is always necessary when a patient is no longer able to declare his or her current wishes. ${ }^{23}$ Does something change in the assessment of the validity of patients' living wills or of the substituted judgements as a result of the information about potential awareness in disorders of consciousness, which were clinically unrecognised before?

If a living will is not available, then the will of the patient is determined by family members or doctors as a substituted judgement. The life concepts and personal wishes of the patient prior to the development of his or her illness are referred to in this case. On the one handas we will subsequently see more clearly - our conception of personal identity is decisive here. Can one presume a diachronic identity for the person even without consciousness or only with evidence of a state of consciousness? If one considers personal identity as existing only when certain states of consciousness are present, then establishing a substituted judgement on this basis could make sense. Just as relevant for a substituted judgement is an assessment of how the patient would have judged a state of being able to perceive and be aware while at the same time being unable to act compared to a state of both being unable to act and being without awareness. Knowledge of the state of awareness in disorders of consciousness is absolutely relevant for making a substituted judgement after such an assessment.

How does the assessment of patients' living wills relate to recent knowledge gained about disorders of consciousness through neuroimaging with regard to their state of awareness? The answer to this question depends on various components of the underlying

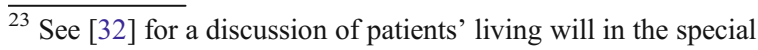
case of the vegatative state.
} 
theoretical assumptions. One such assumption concerns personal identity. Another concerns the understanding of autonomy underlying the living will. I will deal with the latter point first.

If self-determination in the sense of instrumental rationality or reflexive identification with higher-order desires is used to justify the validity of a living will, then the living will is valid in its application despite the discovery through neuroimaging of a clinically unrecognised, potential awareness in disorders of consciousness, unless assumptions of the living will about consciousness and cases of its disorders are false. If the validity of a living will is justified in the way mentioned above, then its validity could only be rendered by false assumptions in the living will or by a current autonomous decision. Neither knowledge of awareness gained from clinical observation in the minimally conscious state nor observation of potential awareness through neuroimaging changes the assessment of non-existing current autonomy in disorders of consciousness as long as there is no possibility of sufficient communication (e. g. with brain-computerinterfaces in a locked-in syndrome).

It is also possible, but very rare in medical ethics, to define autonomy with very strict provisos in a Kantian way. This could, according to some interpreters, even make it impossible to sign a living will, which contains the action maxim to die in cases of disorders of consciousness, independently of the state of awareness. To determine the correctness of such an interpretation is not the subject of this article. However, it should be noted that the assessment of whether a particular living will must be followed is more dependent on the fundamental understanding of autonomy than on knowledge of potential awareness in disorders of consciousness.

With the standard understanding of autonomy meaning self-determination, the turning point for the assessment of a living will in cases of disorders of consciousness seems to rely more on the ability of sufficient communication, which is not verifiable in disorders other than the locked-in-syndrome, rather than signs of awareness through neuroimaging techniques. Such signs, however, could be the beginning of a process ending in facilitating possibilities to communicate sufficiently in cases of misdiagnosed patients, who are in a locked-in state.

The other component of the question whether living wills are valid despite or precisely because of knowledge of potential awareness in disorders of consciousness is the theoretical background of personal identity used in each case. Because this subject is somewhat more complex, I will briefly summarise the various positions to clarify the essential criteria for determining personal identity.

In the debate on personal identity it is - roughly speaking - usually a question of determining when and how we can know that a person at time points $\mathrm{t} 1$ and $\mathrm{t} 2$ is identical. Locke made a significant contribution to such deliberations by postulating both a memory criterion (which he called consciousness) as well as by arguing that personal identity must be a question not of a substance, but rather of a relation. ${ }^{24}$ This criterion has received much criticism, and today many theoreticians consider a continuity of psychological states rather than a memory criterion as essential for personal identity. ${ }^{25}$ For other philosophers including Williams, the continuity of the body is a necessary condition for personal identity. Only if the relation of personal identity is tied to the body can the essential principle of unambiguousness be satisfied for Williams. ${ }^{26}$ The latter criterion was extensively modified over the course of the debate as well. There is thus talk of a 'physical criterion', according to which personal identity is present as long as the brain is sufficiently intact, such that the person is alive. ${ }^{27}$ The various criteria have also been combined with one another in different ways, resulting in an abundance of multi-criteria approaches.

The question that results from the debate about personal identity for the article is: how do particular assumptions about personal identity affect the validity of living wills in cases of disorders of consciousness and under consideration of whether knowledge of a state of awareness is available?

If a physical criterion or a type of body criterion is necessary and sufficient to determine personal identity, then the living will must be considered valid both with and without knowledge of awareness in patients with disorders of consciousness because it refers to the same organism.

If, on the other hand, the relation of personal identity is tied to the continuity of psychological

\footnotetext{
${ }^{24}$ See [29].

${ }^{25}$ Criticism can be found in [36], p.10 ff.

${ }^{26}$ See [55]. For an introduction to and discussion of various criteria of personal identity, see [36].

${ }^{27} \mathrm{See}$ in this regard [36], p. $2 \mathrm{ff}$.
} 
states, then the assumption of awareness may be relevant for the validity of living wills and therefore for decisions concerning whether or not to withdraw artificial nutrition and hydration.

Whether this is the case also depends greatly on the understanding of what the continuity of psychological states requires: with the ability for verbal communication, or with inconsistent and variable (but reproducible and distinguishable from reflexes) reactions and with the assumption of awareness, or with involuntary movements of patients and observable opening of the eyes or with vegetative functions. If for example observations of involuntary movements in patients in a vegetative state are not sufficient to attribute a continuity of psychological states and thus personal identity to patients in a vegetative state, then the living will would no longer be a case of prospective autonomy. The previously established self-determination would then refer to another person and decisions on whether or not to withdraw artificial nutrition and hydration would have to be made using criteria other than the living will. ${ }^{28}$ If, at the same time, signs of awareness would be regarded as sufficient for attributing continuity of psychological states, then new findings through neuroimaging would suspend previous conclusions and the living will would still refer to the same person.

The preceding conclusions may appear drastichowever, it would be a logical consequence of applying certain theories of personal identity. Unlike discussions in philosophy, in debates in medical ethics the criteria for determining personal identity usually (even if often only implicitly) also incorporate the body and physical elements of the person. Nevertheless, this discussion clarifies that the applicability of living wills in cases of disorders of consciousness is absolutely dependent on the underlying theory of personal identity and that, as a result, assumptions about the presence of awareness may make an essential difference to the assessment depending on the theory.

In this regard, one could further differentiate between the different characteristics of consciousness listed earlier and the particular connection with personal identity. For reasons of space, this possibility for further differentiation will only be suggested in the

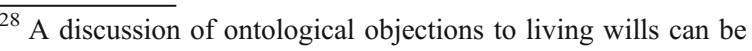
found in [40], p. $190 \mathrm{ff}$.
}

following. Earlier it was presumed that new neuroscientific findings about disorders of consciousness could be indicative of phenomenal consciousness or intentionality rather than self-consciousness, even if they do not preclude it. These could only form a basis for personal identity if continuity of psychological states is a sufficient condition for personal identity. If, on the other hand, memory is applied as a necessary condition in accordance with Locke, then this could hardly be satisfied without self-consciousness. ${ }^{29}$ Correspondingly, one could differentiate even further with regard to the applicability of the living will.

\section{Moral Status, Beneficence and Non-Maleficence}

So far, we have seen that the understanding of both autonomy and personal identity that is used greatly influences normative end-of-life decisions with regard to patients with disorders of consciousness. We have also seen that depending on the theory applied, knowledge of awareness in disorders of consciousness has a varying level of relevance for end-of-life decisions. These results were illustrated using an analysis of the logical consequences of particular ways of understanding autonomy and personal identity in connection with prospective autonomy or autonomy by proxy.

Alongside these considerations, it is also necessary for the applicability of living wills that patients with disorders of consciousness are assigned a moral status. In the following, it is shown by using examples of two opposing moral philosophical approaches that not every theoretical concept requires the moral status to be dependent on the state of awareness. Correspondingly, normative decisions regarding patients with disorders of consciousness that use moral status as a criterion necessarily rely on a moral philosophical theory, but not necessarily on information regarding the state of awareness.

Usually entities such as persons are ascribed moral status if they exhibit properties on the basis of which they must be morally considered in a specific way (for example, through rights and obligations). ${ }^{30}$ The difficulty in the present matter lies in the fact that different moral theories deal with the issue of moral status in greatly differing ways. These differences

\footnotetext{
${ }^{29}$ In this case, memory refers to autobiographical memory.

${ }^{30}$ A detailed discussion on moral status is provided by [43, 53].
} 
result from answers to the following and similar questions: (1) what properties determine moral status? (2) Is there a difference between the justification of the attribution of moral status and the criteria for an actual attribution? (3) Do certain rights or duties necessarily arise from particular properties or from moral status $?^{31}$

A comprehensive theory of the moral status of humans cannot be developed within the scope of this discussion. Yet, the aforementioned questions can serve as signposts in the discussion. (1) A morally relevant characteristic may be the ability to suffer, for example, or the ability to have preferences. A capacity for reason may also be a morally relevant characteristic. The latter are critical in providing a theoretical foundation for human dignity. The list of morally relevant characteristics is in no way exhausted with this list; such characteristics were selected as examples to illustrate the way knowledge regarding the state of awareness affects the end-of-life decisionmaking process differently depending on the philosophical theory presupposed.

The ability to suffer usually requires phenomenal consciousness; depending on the theory, access consciousness may also be required to be able to ascribe a capacity for suffering. The same also applies to the capacity to experience pain. A capacity for experiencing pain or for suffering is usually a morally relevant characteristic. ${ }^{32}$ If the capacity for suffering or perceiving pain is thus the morally relevant characteristic for ascribing moral status to a patient with a disorder of consciousness (1), then findings from neuroscience about possible states of awareness could indeed provide relevant information. ${ }^{33}$ The

\footnotetext{
$\overline{31}$ See also [43].

32 Some even claim that suffering is possible without phenomenal consciousness; see [9]. For a discussion on the difference between these characteristics of consciousness in general, on the possibility of their separate manifestation, and with regard to pain, see [6]. More on the relationship between avoidance of pain and utilitarianism can be found in [33]. For a discussion of the ability to suffer as a condition for having interests, see [48]. ${ }^{33}$ Savulescu and Kahane [44] present various considerations concerning patients in a vegetative state, in a minimally conscious state and in a locked-in syndrome in relation to their state of consciousness, wisdom, experiential interests and the value of life. They ultimately come to the conclusion that "enjoyment of consciousness might actually give stronger moral reasons not to preserve a patient's life, and, indeed, that these might be stronger when patients retain significant cognitive function." (p.1)
}

criteria of actual attribution of this characteristic would be congruent with the practice of justification (2).

With regard to the criteria of attribution for patients with disorders of consciousness, there is, however, an epistemic problem previously addressed regarding findings of neuroimaging. If one presumes the characteristic of being able 'to experience suffering or pain' as being morally relevant, then objections of epistemic uncertainty should not remain unconsidered. In everyday medical-normative decisions with regard to patients with disorders of consciousness, the mere suspicion that capacity for pain and suffering may still be present appears to override these objections and to justify, say, pain medication, assuming one seeks to behave within the meaning of the principles of beneficence and non-maleficence. ${ }^{34}$ If, however, it is a question of end-of-life decisions, then such objections are too substantial for moral status to be determined in this manner.

Epistemic uncertainty also cast significant doubt upon the formulation of conclusions regarding the current well-being of the patient based on the aforementioned findings, and, by extension, on end-of-life decision-making processes that relate to current wellbeing. Wellbeing, which in accordance with the principle of beneficence, must be promoted (according to underlying utilitarian theories) is associated with freedom from pain and suffering in both colloquial usage and commonly in philosophical (usually utilitarian) contexts. Neither clinical assessment nor the results from neuroimaging concerning possible awareness in patients with disorders of consciousness do, however, provide qualitative information about current well-being that would be credible for end-of-life decisions. This conclusion is not based on the assertion of a fundamental independence of well-being from consciousness, but rather that current wellbeing cannot be recognised based on the results discussed.

\footnotetext{
$\overline{34}$ The avoidance of pain and suffering can be the subject of the principle of beneficence, which is concerned with assuring the well-being or benefit of the patient (see [3], chapter 6), as well as the subject of the principle of nonmaleficence, according to which no actions should be taken that harm the patient (see [3], chapter 5). Signs of pain given by patients with disorders of consciousness could be a helpful indication for such harmful actions. To make a sufficient differentiation between beneficence and non-maleficence is not the aim here, more on that see [3], p. 199.
} 
The ability to form preferences - another possible characteristic for justifying and ascribing moral status (1) - is often connected with the requirement of selfconsciousness. ${ }^{35}$ This requirement could be considered as being unsatisfied in patients with disorders of consciousness, depending of the interpretation of recent findings. Should this characteristic be relevant for moral status, then patients with disorders of consciousness could not be ascribed a certain moral status (2).

With regard to human dignity, the situation is quite different. The effort to respect and preserve this dignity can also be interpreted as a far-reaching approach based on the principles of beneficence and non-maleficence. The requirement that humans should never be treated simply as a means but always at the same time as an end is premised on the principle of human dignity. ${ }^{36}$ In line with Kant's reasoning, human dignity must be ascribed to all beings capable of reason (1). According to this moral theory, a capacity for reason and autonomy constitute essential and morally relevant characteristics of humankind. Human dignity is not only associated with autonomy here, but is substantiated by it. Although the definition of autonomy as selflegislation as guided by Kant presupposes the preceding prerequisites of self-determination, it demands more of moral subjects. Moral subjects are obligated to follow action maxims, which can become universal law without contradiction. This goes far beyond what is usually subsumed under autonomy in medical ethical debates. ${ }^{37}$ It was already mentioned earlier that in patients with disorders of consciousness, even weak criteria for self-determination cannot currently be fulfilled, neither clinically nor regarding new neuroscientific findings.

Can these patients therefore not be ascribed moral status on the basis of this moral philosophical theory? In this regard, we must differentiate between the

\footnotetext{
${ }^{35}$ See [21]. For more on preferences and utilitarian theory see [48] and on consequentialism, see [5].

${ }^{36}$ This conception of human dignity enunciated in numerous instances by Kant can be found in [25] VI, p. 462; [25] IV, p. 438, etc.

${ }^{37}$ For more on Kant and autonomy see [1]. Vossenkuhl [52] discusses the possibility of a narrow and broad understanding of autonomy in connection with the principle of respect for autonomy in decision-making processes in medical contexts. $\mathrm{He}$ also asserts that the protection of human dignity is immanent in the principle of non-maleficence.
}

criteria to justify moral status and the criteria for an actual attribution (2). The foregoing discussion relates to the justification. The criteria of attribution are also justified with the potential capacity for reason, which is supposed for all human beings. Therefore corporal living existence of a human is understood in most interpretations of Kantian moral philosophy to be an adequate criterion for attribution. The attribution of moral status does not require the actual exercise of the capacity for reason. The extension of the term human dignity thus also includes cases in which selfdetermination and self-legislation cannot be realised. ${ }^{38}$ The presence of a specific form of awareness is thus not a necessary condition for ascribing moral status to these patients.

However, it is still not certain which rights arise (3) out of this moral status (this is also the case with other justification processes). Although a right to life is usually linked to human dignity, this does not necessarily have to be the case. A duty to life is not usually assumed in most debates about human dignity. ${ }^{39}$ The connection between right to life / duty to live and moral status is thus again dependent on theory.

\section{Conclusion}

Theoretical dependence could thus be consistently demonstrated for the criteria examined here that are relevant for end-of-life decisions involving patients with disorders of consciousness. By contrast, the decision was not established as a result of knowledge of potential awareness for all criteria; rather, the underlying theory was critical for the decision process.

Knowledge of potential awareness beyond clinical assessment in patients with disorders of consciousness and research into this subject can be extremely helpful when there is a need to establish or even justify particular treatment options. Thus, music therapy for example could be justified by the assumption that these patients possess phenomenal consciousness.

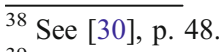

${ }^{39}$ In contrast to dignity, the right to life is not an 'inalienable right' (see suicide); furthermore, in contrast to dignity, it can be balanced (e. g. with autonomy), see [40], p. 48 f. Kant's concept of dignity can be interpreted such that a right to life and duty are both implied; on the subject of the perfect duty and self-preservation, see [25] VI, p. 421.
} 
Similarly, knowledge of possible awareness can influence the contact behaviour of family members. Results of neuroimaging could also help to diminish misdiagnosis, to identify patients in a minimally conscious state or in a locked-in syndrome more precisely and to allow more appropriate prognosis.

If and when, however, the criteria analysed here are used for normative decisions about life-sustaining treatment, then actual available knowledge of a more or less intact awareness in patients with disorders of consciousness only results in a change in the decision situation on whether or not to withdraw artificial nutrition and hydration for example under the application of certain background theoretical assumptions.

Acknowledgements I would like to thank the Institute of Neuroscience and Medicine, Ethics in the Neurosciences (INM8) at the Jülich Research Center and the Institute of Ethics, History, and Theory of Medicine at the Ludwig-MaximiliansUniversity, Munich for supporting my research. Furthermore, I would like to thank the German Federal Ministry of Education and Research for funding the work on this article, which took place at the workshop on "Vegetative State: A Paradigmatic Problem of Modern Society." I am also very grateful for the discussions with the participants at the afore-mentioned workshop and would like to acknowledge the help of my colleagues at the institutes in improving this article, especially Jan-Hendrik Heinrichs, Lisa Tambornino, Dorothee Wagner von Hoff, and Ralf Jox.

Open Access This article is distributed under the terms of the Creative Commons Attribution Noncommercial License which permits any noncommercial use, distribution, and reproduction in any medium, provided the original author(s) and source are credited.

\section{References}

1. Ameriks, K. 2000. Kant and the fate of autonomy. Cambridge: Cambridge University Press.

2. Baumann, P. 2000. Die Autonomie der Person. Paderborn: mentis.

3. Beauchamp, T., and J. Childress. 2009. Principles of biomedical ethics. Oxford: Oxford University Press.

4. Birbaumer, N. 2006. Breaking the silence: Brain-Computer Interfaces (BCI) for communication and motor control. Psychophysiology 43(6): 517-532.

5. Darwall, S. (ed.). 2003. Consequentialism. Oxford: Blackwell Publishing.

6. Block, N. 2002. Concepts of consciousness. In Philosophy of mind: Classical and contemporary readings, ed. D. Chalmers, 206-218. Oxford: Oxford University Press.

7. Boly, M., M. Garrido, O. Gosseries, et al. 2011. Preserved feedforward but impaired top-down processes in the vegetative state. Science. doi:10.1126/science.1202043.
8. Blumenfeld, H. 2009. The neurological examination of consciousness. In The neurology of consciousness. Cognitive neuroscience and neuropathology, ed. S. Laureys and G. Tononi, 15-30. London: Elsevier Academic Press.

9. Carruthers, P. 2004. Suffering without subjectivity. Philosophical Studies 121(2): 99-125.

10. DeGrazia, D. 2003. Common morality, coherence, and the principles of biomedical ethics. Kennedy Institute of Ethics Journal 13(3): 219-230.

11. Di, H.B., S.M. Yu, X.C. Wenig, et al. 2007. Cerebral response to patient's own name in the vegetative and minimally conscious states. Neurology 68(12): 895-899.

12. Eickhoff, S., M. Dafotakis, C. Grefkes, et al. 2008. fMRI reveals cognitive and emotional processing in a long-term comatose patient. Experimental Neurology 214(2): 240-246.

13. Frankfurt, H. 1971. Freedom of the will and the concept of a person. The Journal of Philosophy 68(1): 5-20.

14. Gallagher, Shaun and Dan Zahavi. 2005. Phenomenological approaches to self-consciousness. Stanford encyclopedia of philosophy. Online: http://plato.stanford.edu/entries/ self-consciousness-phenomenological/

15. Gehlen, W., and H. Delank. 2010. Neurologie. Stuttgart: Thieme.

16. Geremek, A. 2009. Wachkoma. Medizinische, rechtliche und ethische aspekte. Köln: Deutscher Ärzte-Verlag.

17. Gert, B., C. Culver, and D. Clouser. 2000. Common morality versus specified principlism: Reply to Richardson. The Journal of Medicine and Philosophy 25(3): 308-322.

18. Giacino, J., and N. Schiff. 2009. The minimally conscious state: Clinical features, pathophysiology and therapeutic implications. In The neurology of consciousness. Cognitive neuroscience and neuropathology, ed. S. Laureys and G. Tononi, 173-190. London: Elsevier Academic Press.

19. Gill-Thwaites, H. 2006. Lotteries, loopholes and luck: Misdiagnosis in the vegetative state patient. Brain Injury 20 (13-14): 1321-1328.

20. Gosseries, O., M.-A. Bruno, A. Vanhaudenhuyse, et al. 2009. Consciousness in the locked-in syndrome. In The neurology of consciousness. Cognitive neuroscience and neuropathology, ed. S. Laureys and G. Tononi, 191-203. London: Elsevier Academic Press.

21. Hauskeller, Michael. 1995. "I prefer not to": Tötungsverbot und Personbegriff in der Ethik Peter Singers. Aufklärung und Kritik, Sonderheft 1. Online: http://www.gkpn.de/ singer3.htm; last certified 28.04.2011.

22. Hildt, E. 2006. Autonomie in der biomedizinischen Ethik. Genetische Diagnostik und selbstbestimmte Lebensgestaltung. Frankfurt: Campus-Verlag.

23. Jackson, F. 1982. Epiphenomenal qualia. The Philosophical Quarterly 32: 127-136.

24. Jox, Ralf. 2011. End-of-life decision making concerning patients with disorders of consciousness. Res cogitans 8 (1).

25. Kant, Immanuel. 1902 ff. Gesammelte Schriften. Edited by the Königlich Preussischen Akademie der Wissenschaften. I-IX Volumes. Berlin: Reimer.

26. Laureys, S. 2004. Functional neuroimaging in the vegetative state. NeuroRehabilitation 19(4): 335-341.

27. Laureys, S., A. Owen, and N. Schiff. 2004. Brain function in coma, vegetative state, and related disorders. Lancet Neurology 3(9): 537-546. 
28. Levine, J. 1983. Materialism and qualia: The explanatory gap. Pacific Philosophical Quarterly 64: 354-361.

29. Locke, J. 2008. An essay concerning human understanding. Oxford: Oxford University Press.

30. Luf, G. 2008. Der Grund für den Schutz der Menschenwürdekonsequentialistisch oder deontologisch. In Menschenwürde. Begründung, Konturen, Geschichte, ed. G. Brudermüller and K. Seelmann, 43-56. Würzburg: Königshausen \& Neumann.

31. Manary, R. 2009. Intentionality and consciousness. Encyclopedia of Consciousness. doi:10.1016/B978-0123738738.00041-4.

32. Mappes, T. 2003. Persistent vegetative state, prospective thinking, and advance directives. Kennedy Institute of Ethics Journal 13(2): 119-139.

33. Mill, J.S. 2006. Utilitarianism. Der Utilitarismus. Stuttgart: Reclam.

34. Monti, M., M. Coleman, and A. Owen. 2009. Neuroimaging and the vegetative state: Resolving the behavioral assessment dilemma? Annals of the New York Academy of Sciences 1157: 81-99.

35. Monti, M., A. Vanhaudenhuyse, M. Coleman, et al. 2010. Willful modulation of brain activity in disorders of consciousness. The New England Journal of Medicine 362(7): 579-589.

36. Noonan, H. 2003. Personal identity. London: Routledge.

37. Owen, A., and M. Coleman. 2008. Using neuroimaging to detect awareness in disorders of consciousness. Functional Neurology 23(4): 189-194.

38. Owen, A., M. Coleman, M. Boly, et al. 2006. Detecting awareness in the vegetative state. Science 313(5792): 1402.

39. Prechtl, P., and F.-P. Burkard (eds.). 2008. Metzler Lexikon Philosophie. Begriffe und Definitionen. Stuttgart: Metzler.

40. Quante, M. 2010. Menschenwürde und personale Autonomie. Demokratische Werte im Kontext der Lebenswissenschaften. Hamburg: Meiner.
41. Quante, M. 2002. Personales Leben und menschlicher Tod. Personale Identität als Prinzip der biomedizinischen Ethik. Suhrkamp: Frankfurt am Main.

42. Racine, E., R. Amaram, M. Seidler, et al. 2008. Media coverage of the persistent vegetative state and end-of-life decision-making. Neurology 71(13): 1027-1032.

43. Rager, G. (ed.). 2009. Beginn, Personalität und Würde des Menschen. Freiburg: Alber.

44. Savulescu, J., and G. Kahane. 2009. Brain damage and the moral significance of consciousness. The Journal of Medicine and Philosophy. doi:10.1093/jmp/jhn038.

45. Schroeder, M. 2004. The scope of instrumental reason. Philosophical Perspectives 18(1): 337-364.

46. Shoemaker, S. 1996. The first-person perspective and other essays. Cambridge: Cambridge University Press.

47. Siewert, Charles. 2011. Consciousness and Intentionality. In: The Stanford Encyclopedia of Philosophy, ed. Edward N. Zalta. http://plato.stanford.edu/archives/fall2011/entries/ consciousness-intentionality/. Accessed 14. 11. 2011.

48. Singer, P. 2011. Practical ethics. Cambridge: Cambridge University Press.

49. Sturma, D. 2005. Philosophie des Geistes. Leipzig: Reclam.

50. Sturma, D. 2007. Person as subject. Journal of Consciousness Studies 14: 77-100.

51. Thagard, P. 1998. Ethical coherence. Philosophical Psychology 11(4): 405-422.

52. Vossenkuhl, W. 2007. Ethische Grundlagen ärztlichen Handelns. In Handbuch des Medizinstrafrechts, ed. C. Roxin and U. Schroth, 3-20. Stuttgart: Boorberg.

53. Warren. 2002. Moral status: obligations to persons and other living things. Oxford: Oxford University Press.

54. Welie, S. 2001. Criteria for patient decision making (in) competence: a review of and commentary on some empirical approaches. Medicine, Health Care and Philosophy 4(2): 139-151.

55. Williams, B. 1973. Problems of the self. Cambridge: Cambridge University Press. 